\title{
Addictions Causing Head-and-Neck Cancers
}

\begin{abstract}
Background: Head-and-neck cancers pose a serious economic burden, with most countries investing significant resources to reduce the incidence, primarily focusing on understanding addictive etiologies. The traditional literature focused on tobacco and alcohol use, with few studies on contemporary factors such as e-cigarette, waterpipe smoking, and human papillomavirus. This article attempts to collate and present an update on the globally identified etiologic factors. Aims: The aim of this study was to identify and review the addictive etiologic factors causing head-and-neck cancers. Methods: An electronic search was performed on Medline, Embase, and Google Scholar to identify the etiologies causing head-and-neck cancers and narrowed down on those driven by addiction. Further, we identified their constituents, mechanism of action, and the risks attributable to various forms of products. Results: Substances identified included smoked and chewed tobacco, alcohol, mate, marijuana, areca nut and betel quid, and viruses. An alarming majority of youth are now utilizing these substances. Furthermore, migrant movements have led to the spread of traditional practices across the regions, especially from the Asian subcontinent. Conclusion: Ironically, despite modern advances and technology, we still see that a large proportion of population succumb to these cancers, emphasizing the need for more effective and targeted policies to combat this menace at the grassroots level.
\end{abstract}

Keywords: Addictions, alcohol, areca nut, betel quid, head-and-neck cancer, marijuana, tobacco, virus

\section{Introduction}

A significant contribution toward the global health burden is from head-and-neck squamous cell carcinoma (HNSCC) - the highest from the lip and oral cavity followed by larynx and oropharynx. ${ }^{[1]}$ In an effort to reduce this load, countries often spend a significant portion of their health-care budget to understand the associated etiology and risk factors. The traditional risk factors include the use of tobacco, alcohol, and areca nut, while the more recent include poor oral hygiene, varied sexual practices, chronic trauma, and dietary deficiencies. ${ }^{[2]} \mathrm{A}$ majority of these are addiction driven, and about $75 \%$ are caused by tobacco, alcohol, and substance use alone. ${ }^{[3]}$ The joint effects of lifestyle-related factors lead to approximately $35 \%$ of the cancer population. ${ }^{[4]}$ An alarming majority of youth are now utilizing these substances developing a shift in the mean age of disease burden in emerging markets even

This is an open access journal, and articles are distributed under the terms of the Creative Commons Attribution-NonCommercial-ShareAlike 4.0 License, which allows others to remix, tweak, and build upon the work non-commercially, as long as appropriate credit is given and the new creations are licensed under the identical terms.

For reprints contact: WKHLRPMedknow_reprints@wolterskluwer.com more than adults. ${ }^{[5]}$ There has also been a surge of novel products, such as the e-cigarette and waterpipe smoking, with companies investing gigantic amounts in branding them to be less hazardous, the effects of which still have to be recognized longitudinally. ${ }^{[6]}$

Kandel popularized the concept of tobacco being a "gateway substance" for alcohol consumption and other substances such as marijuana and cocaine. ${ }^{[7]}$ Studies have shown that adolescents who smoked were 3 times more likely to drink alcohol, 8 times more likely to also smoke marijuana, and 20 times more likely to use cocaine than nonsmoking peers. ${ }^{[8]}$ On the contrary, it is interesting to see that many countries' economies are cripplingly dependent on the production of these leading causes of cancer, especially tobacco. ${ }^{[9]}$ With these addictive substances being used across all strata of society, it is important to understand their varied carcinogenic potential. This article attempts to collate and present an update on these substances used globally that cause HNSCC.

How to cite this article: Singh $A$, Sharin $F$, Singhavi $H$, Sathe $P$, Gnanamoorthy A, Chaturvedi $P$. Addictions causing head-and-neck cancers. Indian J Med Paediatr Oncol 2020;41:510-8.
Arjun Singh ${ }^{1}$, Florida Sharin ${ }^{1}$, Hitesh Singhavi ${ }^{1}$, Pranav Sathe ${ }^{1}$, A Gnanamoorthy ${ }^{2}$, Pankaj Chaturvedi ${ }^{1}$

${ }^{1}$ Department of Head and Neck Oncology, Tata Memorial Hospital and HBNI, Mumbai, Maharashtra, India, ${ }^{2}$ Tata Memorial Hospital and HBNI, Mumbai, Maharashtra, India

Submitted: 17-Mar-2020 Accepted in Revised Form: 29-Jun-2020

Published: 29-Aug-2020

Address for correspondence: Dr. Pankaj Chaturvedi, Department of Head and Neck Oncology, Tata Memorial Hospital and HBNI, Mumbai, Maharashtra, India.

E-mail: chaturvedi.pankaj@ gmail.com

Access this article online Website: www.ijmpo.org DOI: 10.4103/ijmpo.ijmpo_99_20 Quick Response Code:
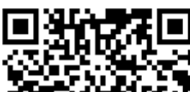

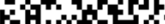

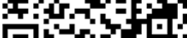




\section{Methods}

We performed an electronic search on Medline, Embase, and Google Scholar to identify the various etiologies causing HNSCC. Our initial search results comprised 284 articles that suggested the role of a substance causing HNSCC. On identifying these agents, we further cross-searched the same databases to narrow down on those driven by addiction and identified studies according to the PRISMA guidelines. On reviewing these articles and their references, we concluded with 54 articles that were categorized into those who identified their constituents and mechanism of action and enlisted the various forms of use globally, along with their associated carcinogenic potential to cause HNSCC.

\section{Results}

\section{Tobacco and its forms}

Tobacco use in all its forms accounts for nearly a third of the global cancer mortality. ${ }^{[1]}$ The initial association was made only for oral cavity, oropharynx, larynx, and hypopharynx but was later extended to include other subsites of the head and neck. ${ }^{[10]}$ The overall risk is proportional to lifetime substance exposure, including the age of initiation, quantity, frequency, number of pack-years, and exposure to secondhand and thirdhand tobacco smoke. ${ }^{[1]}$ Nicotine, a potent parasympathomimetic stimulant, usually constitutes $0.6 \%-3.0 \%$ of the dry weight of tobacco. ${ }^{[12]}$ After inhalation of the smoke, nicotine crosses the blood-brain barrier in $10-20 \mathrm{~s}$ and has a half-life of about $2 \mathrm{~h}^{\text {. }}{ }^{[12]}$

\section{Carcinogenic compounds}

There are 60 confirmed carcinogenic chemicals in tobacco smoke out of its 4000 constituent chemicals, with a majority being Tobacco-Specific Nitrosamines (TSNAs). ${ }^{[13]}$ Once metabolized, they cause DNA alkylation initiating a series of mutagenic events. Others include the polycyclic hydrocarbons, aromatic hydrocarbons, and catechols, all of which supplement the TSNAs. ${ }^{[13]}$

About 28 carcinogens have been identified in smokeless tobacco, formed during aging and curing. Others present include volatile aldehydes, benzo $[a]$ pyrene, urethane, certain lactones, arsenic and nickel, uranium-235 and uranium-238, and polonium-210. ${ }^{[14]}$ The overall nicotine absorption is slower compared to cigarettes, but about 3-4 times greater nicotine per dose is absorbed. Chewing or dipping smokeless tobacco $8-10$ times per day may deliver a similar amount of nicotine as smoking 30-40 cigarettes per day. ${ }^{[15]}$

\section{Mechanism of action}

Once these carcinogens are absorbed, they require activation by cellular enzymes, such as the cytochrome p450 group, while detoxifying enzymes offset these effects. The induction of somatic genetic mutations is equally important to drive the tumor pathogenesis, which are either proto-oncogenes or inhibitors of tumor suppressor genes. ${ }^{[13]}$ The common molecular enzyme signaling pathways affected are the p53 pathway, retinoblastoma pathway, epidermal growth factor pathway, and the PI3-kinase pathway. All of these events along with local mucosal changes due to chronic trauma or injury lead to the eventual development of a cancerous lesion. ${ }^{[13]}$

\section{Smoked tobacco}

Smoking is the single most preventable cause of cancer with the highest users in the WHO European region $(75.3 \%)^{[1,5]}$ The association of smoked tobacco and cancer was initially studied in 1915, where the habit was commonly seen among oral cavity lesions [Table 1]. ${ }^{[16]}$ Countries having more adolescent than adult smokers among males include Ethiopia, Nigeria, Qatar, and Senegal, while in females, include Argentina, Costa Rica, Egypt, Kenya, Mexico, Pakistan as well as the countries mentioned before. Countries with a very high human development index have shown a reduction in the rate of tobacco use among the youth ${ }^{[5]}$ A meta-analysis has shown that the odds of getting oral cancer was 4.65 times higher than nonsmokers, with the highest rates in the American continent (odds ratio $[\mathrm{OR}]=7.65)$ and the lowest in Asia $(\mathrm{OR}=1.88) .{ }^{[17]}$

\section{Cigarettes}

Blond variety of tobacco is the most commonly used form globally, with around $8 \mathrm{mg}$ of total nicotine available in a commercial cigarette. Menthol cigarettes have become popular due to their flavor and increased half-life due to the inhibition of nicotine-to-cotinine metabolism. ${ }^{[18]}$ The tonsillar crypts, glossotonsillar sulcus, and base of the tongue are commonly affected due to the prolonged exposure of the pooled saliva. The relative risk for developing cancers in the upper aerodigestive tract increases with the number of cigarettes smoked daily and the duration of years. The risk is also proportional to the number of years after quitting, with the exception of esophageal cancers. ${ }^{[17]}$ Lubin et al. found that a greater number of cigarettes smoked per day for a short duration were less deleterious than fewer cigarettes per day for a longer duration. ${ }^{[19]}$

\section{Cigar and pipes}

A typical cigar is made of dried dark tobacco leaves that are rolled into a bundle which is available in a variety of grades and sizes. The most common forms include the coronas or parejo that are predominantly manufactured in Southeast Asian and South American countries. The smoke from cigars is not inhaled and often rolled around the mouth. Similarly, pipe smoking was also traditionally meant for tobacco tastings. This may lead to a stronger association with oral cancer than other forms of smoked tobacco. Parkin et al. have found that pipe use had a similar risk of developing oral and oropharyngeal cancers as that 


\begin{tabular}{|c|c|c|c|}
\hline \multicolumn{4}{|c|}{ Table 1: Smoked forms of tobacco } \\
\hline Product & Region & Preparation & Site of cancer \\
\hline Cigarettes & Worldwide & $\begin{array}{l}\text { Blended tobacco (most often blond) } \\
\text { packed into paper rolls }+ \text { filter }\end{array}$ & $\begin{array}{l}\text { Upper aerodigestive tract } \\
\text { Lung }\end{array}$ \\
\hline Cigar and pipes & $\begin{array}{l}\text { North and South America } \\
\text { UK } \\
\text { Australia } \\
\text { Mediterranean }\end{array}$ & $\begin{array}{l}\text { Dark tobacco }+ \text { packed into binder leaf } \\
\text { and rolled }\end{array}$ & $\begin{array}{l}\text { Oral } \\
\text { Oropharynx } \\
\text { Lung }\end{array}$ \\
\hline Beedi & Asian subcontinent & Tobacco + packed into tendu leaf rolls & $\begin{array}{l}\text { Oral commissure } \\
\text { Tongue }\end{array}$ \\
\hline Waterpipe/hookah & $\begin{array}{l}\text { Arab world } \\
\text { Global incidence increasing } \\
\text { rapidly }\end{array}$ & Tobacco + special waterpipe & $\begin{array}{l}\text { Oral } \\
\text { Oropharynx } \\
\text { Lung }\end{array}$ \\
\hline Reverse chutta smoking & $\begin{array}{l}\text { India } \\
\text { Bangladesh } \\
\text { Pakistan }\end{array}$ & $\begin{array}{l}\text { Any of above smoked with cherry } \\
\text { reversed }\end{array}$ & Hard and soft palate \\
\hline Secondhand/passive smoking & Worldwide & - & $\begin{array}{l}\text { Pharynx } \\
\text { Larynx } \\
\text { Lung }\end{array}$ \\
\hline
\end{tabular}

of cigarettes $(\mathrm{OR}=3.8$ and 3.9 , respectively) while cigar smoking was double $(\mathrm{OR}=8.3) .{ }^{[20]}$ Another study by Wyss et al. from the INHANCE consortium found that the risk for HNSCC was higher in exclusive cigar $(\mathrm{OR}=3.49)$ and pipe smokers $(\mathrm{OR}=3.71)$, suggesting their independent association with these cancers. ${ }^{[21]}$

\section{Beedi}

This is a hand- or machine-rolled form of cigarette wrapped in tendu or temburni leaf used most commonly in the Indian subcontinent. It commonly causes cancers of the oral commissure and entire tongue. Rahman et al.'s meta-analysis showed that beedi smoking had a higher $\mathrm{OR}$ of 3.1 compared to cigarette smoking $(\mathrm{OR}=1.1)$ in causing oral cancer. ${ }^{[22]}$

\section{Waterpipe smoking or hookah/shisha/narghile}

With its origins in the Middle East, this form of tobacco smoking has gradually gained popularity among the youth subsequent to the introduction of flavored tobacco (maassel). ${ }^{[23]}$ Waterpipe smoking is the most common method of tobacco smoking than any other form in the Arab world. ${ }^{[24]}$ Overall, the prevalence rates range from $0.9 \%$ in Oman to $34.2 \%$ in Lebanon. ${ }^{[25]} \mathrm{A}$ meta-analysis found that its association increased the risk of HNSCC $(\mathrm{OR}=2.97)$, esophageal cancer $(\mathrm{OR}=1.84)$, and lung cancer $(\mathrm{OR}=2.22) \cdot{ }^{[24]}$

\section{Reverse chutta/addapoga}

This form is more common in the rural indigenous population of the Asian subcontinent. It is related to cancers of the hard palate and associated structures due to maximum local exposure of heat with carcinogen, seen especially higher among women. ${ }^{[26]}$

\section{E-cigarettes}

E-cigarette is a contemporary form of noncombustible nicotine use. There is no clear evidence whether they aid in tobacco cessation. While population studies have shown that smokers have successfully quit smoking with the help of e-cigarettes, randomized trials and cohort studies have not been able to demonstrate the same. It is also associated with many side effects such as dry mouth or sore throat, cough, dizziness, headache, mouth or tongue sores, sleeplessness, palpitations, breathing problems, allergies, fatigue, nose bleeding, chest pain, stress, and gum bleeding. ${ }^{[27]}$ There is also evidence of substantial experimentation among the youth, even among never-smokers, suggesting a possibility of a new "gateway" substance. ${ }^{[28]}$ The epidemiological evidence of its long-term health effects is still to be seen and might take decades to make final conclusions. India has recently banned the manufacturing, distribution, import, and sale of all electronic nicotine delivery systems. Not only India but also other countries such as Argentina, Taiwan, Singapore, Jordan, Lebanon, Malaysia, Cambodia, Columbia, Egypt, Mexico, Singapore, Brazil, Thailand, and Vietnam have imposed ban with varying levels of success. ${ }^{[29]}$

\section{Secondhand or passive smoking}

More than 7 million people die due to tobacco smoking every year, while about $12 \%$ of these are due to secondhand smoke exposure. ${ }^{[30]}$ Most studies available show a relation between environmental tobacco smoke and lung cancer, while few are present indicating a link to HNSCC. ${ }^{[31]}$ Although the duration was not specified, Lee et al. showed that a long period of passive smoking increased the risk of HNSCC by $1.55-1.6$ times that was stronger for pharyngeal and laryngeal cancers. ${ }^{[32]}$ 


\section{Thirdhand smoking}

Residual tobacco pollutants including tobacco-specific nitrosamines, 3-ethenylpyridine, phenols, cresols, naphthalene, and formaldehyde remain in dust or on surfaces after smoking, and these react with oxidants to yield secondary pollutants or are re-emitted into gaseous state. Thirdhand smoke is pervasive and ubiquitous and its presence on surfaces and dust creates multiple routes of exposure. Because of increased exposure and sensitivity to various pollutants, children and infants account for the most vulnerable population. ${ }^{[33]}$

\section{Smokeless oral}

Cancers arising in these smokeless tobacco (SLT) users are more often at the site of quid placement, usually being the oral and oropharynx [Table 2]. Over 250 million people in the Southeast Asia region use SLT, representing about
$17 \%$ of the population (82\% live in India). ${ }^{[14]}$ Siddiqi et al. studied the burden of SLT consumption across 113 countries and found that they were 3.43 times more likely to develop oral cancers, commonly of the tongue and lips. ${ }^{[34]}$ Even the potentially malignant lesions have a higher incidence among SLT users.

A product with a higher $\mathrm{pH}$ delivers more protonated nicotine that adds to a higher potential of toxicity. The highest $\mathrm{pH}$ values are seen in naswar from Uzbekistan and toombak from Sudan. ${ }^{[14]}$ Over the years, the $\mathrm{pH}$ values are declining possibly leading to reduced habitual behaviors. Ammonium and sodium carbonate (chunna) are often added as alkylating agents to the tobacco products to enhance absorption. With high use in the South Asian countries, a strong association has been found for oral cancers varying among the betel quid users from 3.1 to 15.7 , while for other types of smokeless tobacco from 1.2 to $12.9 .^{[35]}$ Among

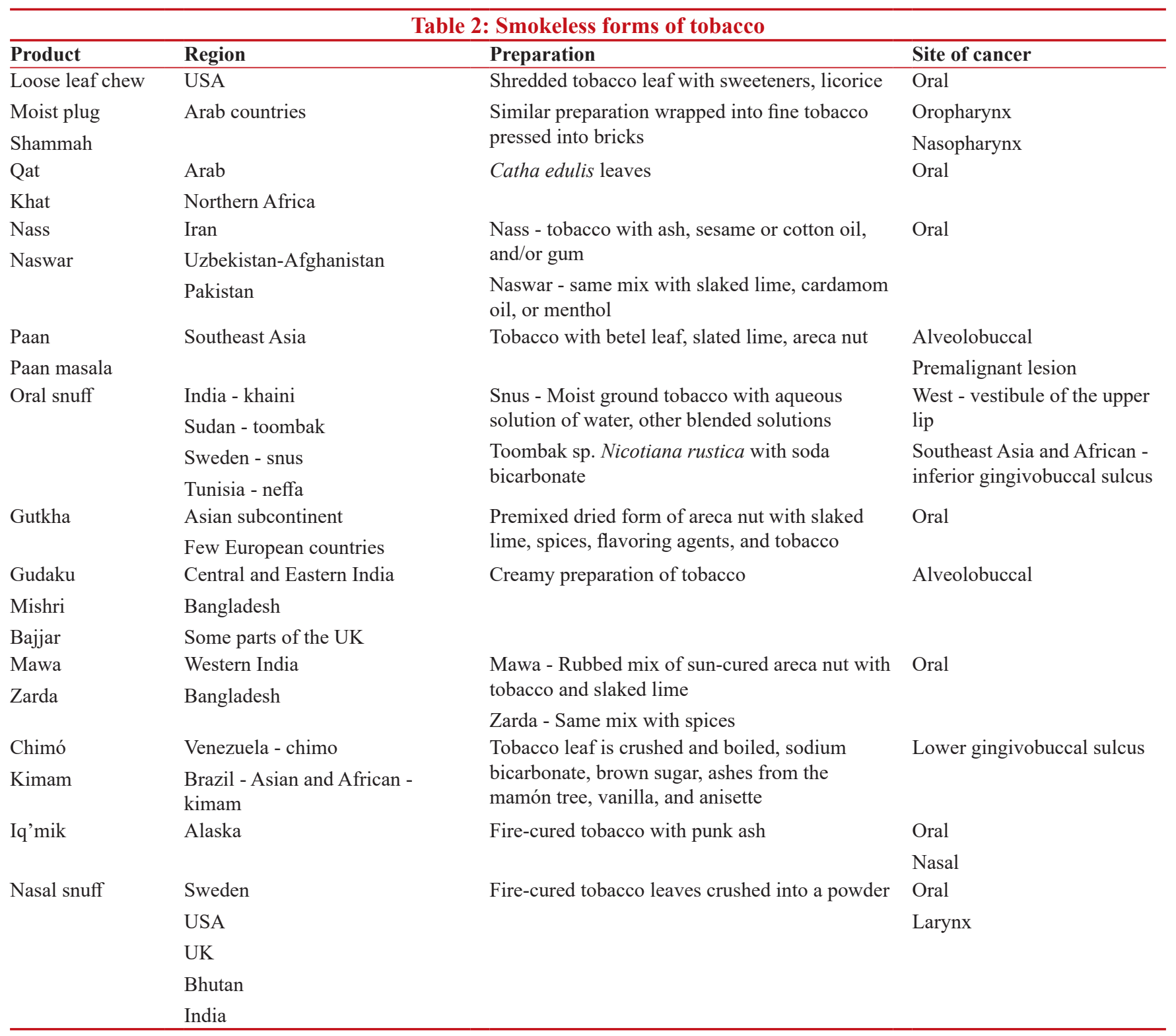


the subsites, the highest OR of 5.5 has been shown to be among oral cancers while it is almost half for the pharynx and larynx (2.69 and 2.84, respectively). ${ }^{[36]}$

\section{Loose leaf chew/shammah and qat}

Sold primarily in the USA, loose leaf chew is the simplest form of chewed tobacco. Moist plug is the same preparation that is pressed into brick-like forms. The Arab equivalent is shammah. It causes oral, oropharyngeal, and nasopharyngeal carcinomas as it is commonly held at the posterior aspect of the oral cavity. ${ }^{[37]}$ Qat or khat (Catha edulis) is a shrub whose leaves are chewed to deliver euphoric effects due to the amphetamine and cathinone. It is consumed in the Arab region and North Africa and can lead to hysteria and even psychosis. Qat-related oral cancer is often initiated by mucosal keratosis. Its carcinogenic effects are established by inducing mutations along with various embryogenic and teratogenic effects. ${ }^{[14]}$

\section{Nass and naswar and mishri}

Nass is a mixture of tobacco and ash with flavorings such as sesame or cotton oil with little water. Gum is sometimes added to make it chewy. When the same is rubbed with slaked lime and cardamom oil or menthol, it is referred to a naswar. ${ }^{[38]}$ Products used in the rural parts of Central and East India and Bangladesh are gul or mishri, often used as a teeth cleaning abrasive, while bajjar is used on the gums. Central Asian countries such as Iran, Afghanistan, and Pakistan have a high consumption of these substances. Hence, alveolar cancers are common among these users. Ipco, as marketed in the Indian subcontinent, is also popular among migrant communities in some parts of the UK as a creamy snuff, primarily among women. ${ }^{[38]}$

\section{Paan and gutkha}

A customary form of SLT use called "paan" is tobacco, slaked lime, and areca nut mixed on a betel leaf. In Southeast Asia, a flavoring agent or sweetener is added and consumed as a mouth freshener. The release of alkaloids is accelerated due to the reduction of $\mathrm{pH}$ by the lime. Paan chewing is associated with high rates of alveolobuccal cancers and premalignant lesions. ${ }^{[14]}$

Gutkha is a premixed form of the above ingredients available either in manufactured or indigenous packaging. It is the most advertised form of tobacco in the Asian subcontinent making it increasingly popular among the youth. Gutkha has been shown to cause genotoxicity and carcinogenesis. ${ }^{[39]}$ Due to this, Indian states have started restricting the manufacture and distribution of these substances. ${ }^{[40]}$

\section{Oral snuff}

In India, a mix of ground moist tobacco and lime is referred to as khaini, while toombak is the Sudanese form of the same preparation. Sweden has the highest consumption and sale of snuff per capita in the world. It is available either as a portioned loose product, often rolled into a ball called a "saffa, weighing about 10 g." Each pinch or dip is placed in the vestibule of the upper lip in Western countries and in the inferior gingivobuccal sulcus in Southeast and African countries. ${ }^{[34,41]}$ The $\mathrm{pH}$ and the unprotonated nicotine are brand specific, ranging from 5.4 to $8.4 .^{[42]}$ The traditional Tunisian "neffa" has a similar content. Approximately $90 \%$ of the tobacco products in Algeria are used in the manufacture of snuff. ${ }^{[43]}$ Low TSNA snuff is being marketed as a safe product as hard snuff or lozenges.

\section{Chimó or kimam and iq'mik}

The most common form of SLT in Venezuela is Chimó. Tobacco leaves are crushed and boiled with sodium bicarbonate, brown sugar, and ashes from the mamón tree to make a thick paste which is seasoned with a flavoring agent. Its use has increased exponentially among young children with a study showing one in ten among 13-16-year-old boys using it. ${ }^{[44]}$ A similar paste is used in Africa made with cardamom or saffron called kimam or qiwam. It is placed in the lower gingivobuccal sulcus that causes cancers of the lower alveolus. Iq'mik is a form of fire-cured tobacco mixed with punk ash, used by almost half of Alaskan natives, which includes teething babies. ${ }^{[45]}$ A small piece is chewed until soft that often lasts throughout the day.

\section{Smokeless nasal}

Dry snuff

The snuff is prepared by fire curing the tobacco leaves and crushing them into a powder. Since it is sniffed, it is associated with sinonasal or nasopharyngeal cancers. It is very popular in Sweden and the USA. Approximately 8\% of Bhutanese use oral or nasal snuff in a country where tobacco sale is prohibited. ${ }^{[46]}$ Sankaranarayanan et al. found that a 3 times higher relative risk of developing tongue, floor of mouth, gingiva, and buccal mucosa cancers exists among snuff users compared to nonusers. They also found a 1.2 times higher risk of developing laryngeal cancers among snuff inhalers. ${ }^{[14]}$

\section{Alcohol}

After tobacco, alcohol is the second most common preventable cause of cancer. It has a multiplicative effect when used with tobacco, establishing a strong role as a co-carcinogen. ${ }^{[47]}$ The National Institute on Alcohol Abuse and Alcoholism reports that alcohol is responsible for 5.9\% of the total deaths globally. ${ }^{[48]}$ Binge drinking, especially among teenagers and students, contributes three-quarters of the total misuse cost in the USA. ${ }^{[49]}$

Goldstein et al. studied the association between alcohol use and oral/oropharyngeal cancer and found that beer had the highest risk in the USA while wine had the lowest. In Italy and Switzerland, the highest risk was associated with 
wine, while among the Swedish, beer and liquor were the highest. Cuba and Brazil had the highest risk among hard liquor drinkers, while in Uruguay, it was wine. Arrack had the highest risk in India. ${ }^{[4]}$ The hypopharynx has the strongest association, while the glottis and subglottis have the least.

\section{Mechanism of action}

On ingestion of alcohol, its metabolism to acetaldehyde is important for its carcinogenic effect. Acetaldehyde exerts its effect by binding to DNA and altering the methyl transfer pathways resulting in genetic hypomethylation, eventually leading to transcription of multiple genes. The reactive oxygen species further contribute to the mutations promoting the p450 cytochrome activity similar to tobacco. Locally, it acts as a solvent to increase the permeability of mucosa. Chronic alcoholics also have a lowered immunity and nutritional status, which further aggravates the process. Consumption causes a release of excitatory and inhibitory neurotransmitters such as dopamine and GABA. Some studies have also shown a direct increase in the release of endorphins on consumption. ${ }^{[14]}$

\section{Quantity of alcohol}

The relative risk of developing oral cancer among alcohol users ranges from 3.2 to 9.2 for people who consume $>60 \mathrm{~g} /$ day (equivalent to 4 drinks/day). ${ }^{[47]}$ Zhang et al. in their meta-analysis divided 13,830 patients into light drinkers $(\leq 12.5 \mathrm{~g} /$ day $)$, moderate drinkers (12.6-49.9 g/day), and heavy drinkers $(\geq 50 \mathrm{~g} /$ day). They found that the OR for developing HNSCC was 1.29, 2.67 , and 6.63 , respectively, for the previously mentioned quantities. ${ }^{[50]}$ It is also shown that more number of drinks per day over a shorter duration are more deleterious than fewer drinks consumed daily for a longer duration. They also found a stronger relation proportional to drink-years than drinks consumed daily for oral cavity and pharyngeal cancer risk. ${ }^{[19]}$

\section{Maté or chimarrão}

Maté is a popular beverage mainly consumed in South America. It is similar to tea in that it is made from fermented leaves and stems of Ilex paraguariensis or yerba maté. Most of its carcinogenic potential comes from phenolic compounds, tannins, and N-nitroso compounds. ${ }^{[14]}$ It is mainly consumed in the South American continent and in lesser amounts in Syria, Northern Israel, and Lebanon. A meta-analysis calculated an increased risk $(\mathrm{OR}=2.11)$ of developing oral cancer in mate users. ${ }^{[51]} \mathrm{A}$ dose-disease relation study by Stefani et al. showed that the highest risk of developing upper aerodigestive tract cancer and laryngeal cancer was with consumption of $>2 \mathrm{l} /$ day $(\mathrm{OR}=1.37$ and $\mathrm{OR}=1.54$, respectively) and in mouth cancers was with $1-1.91 /$ day $(\mathrm{OR}=1.03)$, while the highest overall risk was for esophagus $(\mathrm{OR}=3.09) \cdot{ }^{[52]}$ Brazilian group found that maté at a very hot temperature had a 3-fold increase risk of oropharyngeal cancers than when consumed hot. ${ }^{[33]}$

\section{Marijuana}

After tobacco, marijuana is the most commonly smoked recreational substance. It has been associated with similar upper and lower respiratory pathologies and cancers. Their carcinogenicity is due to the cytogenetic changes that are induced after activation. ${ }^{[54]}$ There are very few studies linking HNSCC with long-term marijuana use and all point toward a younger age of incidence resulting in more aggressive disease. Contrary to this notion, a meta-analysis by de Carvalho et al. suggested no strong association between exposure and disease with a relatively low OR of $1.021 .{ }^{[55]}$

\section{Areca nut and betel quid}

The areca nut is the seed of the fruit of the areca palm that is predominantly consumed in Africa, South America, Taiwan, and the Indian subcontinent. Its consumption is deeply integrated into cultural and religious activities in these regions. The Taiwanese usually do not add tobacco and have reported a relative risk of 58.4 of developing oral cancer among their population. ${ }^{[56]}$ A higher risk of developing esophageal cancer is present in this population because they swallow the liquid extract, as opposed to tobacco chewers who spit it out in other parts. The risk further increases by 8.4 times when tobacco is added. ${ }^{[57]}$ In certain parts of India, $87 \%$ of women chew areca nut as compared to only $49 \%$ of men. ${ }^{[58]}$ The habit has a strong association with potentially malignant disorders such as submucous fibrosis. The areca nut contains alkaloids (arecoline, arecaidine, guvacine, and guvacoline) and flavonoids (tannins and catechins) that have a cytotoxic effect on cells and promote collagen synthesis. The constant irritation from the chewing habit leads to a T-cell and transforming growth factor-beta-mediated chronic inflammation, further adding to the fibrosis. ${ }^{[59]}$

During areca nut chewing, the oral mucosa is persistently stimulated by the areca nut extracts and arecoline, which causes induction of c-Jun proto-oncogene. This proto-oncogene encodes a nuclear protein $(39 \mathrm{kDa})$ which is a major component of the mammalian transcription factor activator protein-1 (AP-1), and it is involved in cellular transformation, multiplication, and apoptosis. c-Jun activation or overexpression has been found in many human malignancies. This may be one of the mechanisms for causing oral cancers. ${ }^{[60]}$

\section{Viruses}

Majority of the literature on HPV-associated HNSCC comes from the west, with the highest association with oropharyngeal subsites, independent of tobacco and alcohol. ${ }^{[59]}$ This association has been shown across numerous case-control studies globally, with risk ranging from 3.6 to 230 for oral oncogenic HPV infection. ${ }^{[61]}$ The typical presentation of a HPV-positive HNSCC is in a young male, having a small primary tumor and a large 
regional nodal metastasis, without the traditional risk factors (tobacco, alcohol, etc.). ${ }^{[59]}$ Tobacco-related HPV-positive cancers might be a different entity altogether as reported by their atypical behavior in many Indian studies. ${ }^{[62]}$ A systematic review suggests a significantly increased risk of developing oral and oropharyngeal cancers proportional to the number of lifetime sexual partners and practice of oral sex and homosexual relations. The other parameters, though inconsistent, included younger age at first engagement, lifetime oral and oral-anal sex partners, and ever performing anal sex. ${ }^{[63]}$

\section{Discussion}

\section{Summary of key findings}

Despite the overwhelming evidence against tobacco, over a billion people still smoke today. ${ }^{[28]}$ Early on, a significant contributor included the media. Magazines such as Cigar Aficionado and Smoke and advertising campaigns such as the Marlboro Man revolutionized the marketing of tobacco products by associating it with a desirous lifestyle. ${ }^{[64]}$ While smoking has declined in high-income countries, it is constantly on the rise in low- or middle-income countries accounting for $80 \%$ of burden..$^{[1,30]}$

These habitual practices have also seen wide international adoption. Due to rapid migration, traditional practices are spreading across borders. The majority of quid consumption is made up of Asian and Arab immigrants. ${ }^{[65,66]}$ Similarly, the practice of waterpipe/hookah smoking is also emerging to be the next big killer. ${ }^{[24,25]}$ Administrations need to focus their resources in understanding these culture-centric habits and design tailored programs to redress their usage. Another approach is to create awareness of these less popularized indigenous habits by including them in the national list of health hazards.

The use of novel products such as e-cigarettes has increased recently. In 2014, they were the most commonly used tobacco product by the youth, with a third having tried them at least once. ${ }^{[8]}$ Among these, 25\% are dual and $21 \%$ are multiple product users ${ }^{[67]}$ [Table 3].

\section{Implications}

These factors underscore the need for youth-centered addiction awareness and control programs. An increase in taxation of these substances has proved successful as the youth are most sensitive to these measures. ${ }^{[28]}$ The Cigarettes and Other Tobacco Products Act (COTPA) 2003 enacted by the Indian Parliament bans the sale of tobacco products near an educational institution. According to Section 6, it is deemed illegal to sell these products within a 100-yard radius of an educational institution. In order to protect children from the harms of tobacco addiction, the Juvenile Justice Act was amended in 2015 that now includes 7-year imprisonment and/or 100,000 fine and enforcement of other provisions of COTPA related to
Table 3: Risk of developing head-and-neck cancer

\begin{tabular}{lll}
\hline Etiologic agent & Subsite & Odds ratio/risk ratio \\
\hline Smoked tobacco & Oral & $1.18-7.6^{[17]}$ \\
Passive smoking & Head and neck & $1.55-1.6^{[30]}$ \\
Smokeless tobacco & Oral & $1.2-12.9^{[32]}$ \\
& Pharynx & $2.69^{[33]}$ \\
& Larynx & $2.84^{[33]}$ \\
& Floor of mouth & $2.73-6.17^{[68]}$ \\
Alcohol & Oral cavity and & $3.2-9.2^{[43]}$ \\
& pharynx & \\
Mate & Floor of mouth & $2.53-3.33^{[68]}$ \\
Marijuana & Oral & $2.11^{[47]}$ \\
Areca nut/betel quid & Head neck & $1.02^{[52]}$ \\
HPV & Oral & $58.4^{[52]}$ \\
& Oral cavity and & $3.6-230^{[56]}$ \\
\hline
\end{tabular}

HPV: Human papillomavirus

tobacco. ${ }^{[69]}$ Opportunistic screening programs stressing on lifestyle modifications are the most important key in reducing the burden of oral cancers, especially in less developed countries.

\section{Conclusion}

A large proportion of the population is still at risk of these cancers driven by addiction. It is of the utmost importance that policy decisions be taken based on the evidence provided in this review as more numbers of youngsters are being driven towards these habits without known the dire consequences.

\section{Financial support and sponsorship}

Nil.

\section{Conflicts of interest}

There are no conflicts of interest.

\section{References}

1. Ferlay J, Soerjomataram I, Ervik M, Dikshit R, Eser S, Mathers C, et al. GLOBOCAN 2012 v1.0, Cancer Incidence and Mortality Worldwide: IARC CancerBase No. 11. Lyon, France: International Agency for Research on Cancer; 2013. Available from: http://globocan.iarc.fr. [Last accessed on 2018 Mar 20].

2. Sankaranarayanan $\mathrm{R}$, Ramadas $\mathrm{K}$, Amarasinghe $\mathrm{H}$, Subramanian S, Johnson N. Oral Cancer: Prevention, Early Detection, and Treatment. In: Gelband H, Jha P, Sankaranarayanan R, Horton S, editors. Cancer: Disease Control Priorities, Vol. 3, $3^{\text {rd }}$ ed. Washington (DC): The International Bank for Reconstruction and Development/The World Bank; 2015.

3. Blot WJ, McLaughlin JK, Winn DM, Austin DF, Greenberg RS, Preston-Martin S, et al. Smoking and drinking in relation to oral and pharyngeal cancer. Cancer Res 1988;48:3282-7.

4. Weiderpass E. Lifestyle and cancer risk. J Prev Med Public Health 2010;43:459-71.

5. Mackay J, Eriksen MP, World Health Organization. The Tobacco Atlas. Geneva: World Health Organization; 2002.

6. Schraufnagel DE, Blasi F, Drummond MB, Lam DC, Latif E, Rosen MJ, et al. Electronic cigarettes. A position statement of 
the forum of international respiratory societies. Am J Respir Crit Care Med 2014;190:611-8.

7. Kandel DB, Yamaguchi K, Chen K. Stages of progression in drug involvement from adolescence to adulthood: Further evidence for the gateway theory. J Stud Alcohol 1992;53:447-57.

8. U.S. Department of Health and Human Services. E-Cigarette Use among Youth and Young Adults: A Report of the Surgeon General-Executive Summary. Atlanta, GA: U.S. Department of Health and Human Services, Centers for Disease Control and Prevention, National Center for Chronic Disease Prevention and Health Promotion, Office on Smoking and Health; 2016.

9. Warner KE. The economics of tobacco: Myths and realities. Tob Control 2000;9:78-89.

10. Parkin DM, Bray F, Ferlay J, Pisani P. Global cancer statistics, 2002. CA Cancer J Clin 2005;55:74-108.

11. Maier H, Dietz A, Gewelke U, Heller WD, Weidauer H. Tobacco and alcohol and the risk of head and neck cancer. Clin Investig 1992;70:320-7.

12. Le Houezec J. Role of nicotine pharmacokinetics in nicotine addiction and nicotine replacement therapy: A review. Int J Tuberc Lung Dis 2003; 7:811-9.

13. IARC. Tobacco Smoke and Involuntary Smoking. IARC Monogr EvalCarcinog Risks Hum 2004a; 83:1-1438.

14. IARC Working Group on the Evaluation of Carcinogenic Risks to Humans. Smokeless Tobacco and Some Tobacco-specific N-Nitrosamines. Lyon (FR): International Agency for Research on Cancer; 2007. (IARC Monographs on the Evaluation of Carcinogenic Risks to Humans, No. 89.) Available from: https:// www.ncbi.nlm.nih.gov/books/NBK326497/. [Last accessed 2019 Jul 26].

15. Cullen JW, Blot W, Henningfield J, Boyd G, Mecklenburg R, Massey MM. Health consequences of using smokeless tobacco: Summary of the Advisory Committee's report to the Surgeon General. Public Health Rep 1986;101:355-73.

16. Abbe R. Cancer of the mouth; the case against tobacco. New York Med. J 1915;102:1-2.

17. Sadri G, Mahjub H. Tobacco smoking and oral cancer: A meta-analysis. J Res Health Sci 2007;7:18-23.

18. Benowitz NL, Herrera B, Jacob $\mathrm{P} 3^{\text {rd }}$. Mentholated cigarette smoking inhibits nicotine metabolism. J Pharmacol Exp Ther 2004;310:1208-15.

19. Lubin JH, Purdue M, Kelsey K, Zhang ZF, Winn D, Wei Q, et al. Total exposure and exposure rate effects for alcohol and smoking and risk of head and neck cancer: A pooled analysis of case-control studies. Am J Epidemiol 2009;170:937-47.

20. Parkin DM, Pisani P, Ferlay J. Estimates of the worldwide incidence of 25 major cancers in 1990. Int J Cancer 1999;80:827-41.

21. Wyss A, Hashibe M, Chuang SC, Lee YC, Zhang ZF, Yu GP, et al. Cigarette, cigar, and pipe smoking and the risk of head and neck cancers: Pooled analysis in the International Head and Neck Cancer Epidemiology Consortium. Am J Epidemiol 2013;178:679-90.

22. Rahman M, Sakamoto J, Fukui T. Bidi smoking and oral cancer: A meta-analysis. Int J Cancer 2003;106:600-4.

23. Maziak W, Taleb ZB, Bahelah R, Islam F, Jaber R, Auf R, et al. The global epidemiology of waterpipe smoking. Tob Control 2015;24 Suppl 1:i3-12.

24. Mamtani R, Cheema S, Sheikh J, Al Mulla A, Lowenfels A, Maisonneuve P. Cancer risk in waterpipe smokers: A meta-analysis. Int J Public Health 2017;62:73-83.

25. Kheirallah KA, Alsulaiman JW, Mohammad HA, Alzyoud S, Veeranki SP, Ward KD. Waterpipe tobacco smoking among Arab youth; a cross-country study. Ethn Dis 2016;26:107-12.

26. Pindborg JJ, Mehta FS, Gupta PC, Daftary DK, Smith CJ. Reverse smoking in Andhra Pradesh, India: A study of palatal lesions among 10,169 villagers. Br J Cancer 1971;25:10-20.

27. Volesky KD, Maki A, Scherf C, Watson LM, Cassol E, Villeneuve PJ. Characteristics of e-cigarette users and their perceptions of the benefits, harms and risks of e-cigarette use: Survey results from a convenience sample in Ottawa, Canada. Health Promot Chronic Dis Prev Can 2016;36:130-8.

28. Farsalinos K. Electronic cigarettes: An aid in smoking cessation, or a new health hazard? Ther Adv Respir Dis 2018;12:1-20.

29. Dyer O. India bans e-cigarettes by executive order. BMJ 2019;366:15649.

30. WHO Fact Sheets. WHO Report on the Global Tobacco Epidemic; 2017. Available from: http://www.who.int/news-room/ fact-sheets/detail/tobacco. [Last accessed on 2018 May 10].

31. Taylor R, Najafi F, Dobson A. Meta-analysis of studies of passive smoking and lung cancer: Effects of study type and continent. Int J Epidemiol 2007;36:1048-59.

32. Lee YC, Boffetta P, Sturgis EM, Wei Q, Zhang ZF, Muscat J, et al. Involuntary smoking and head and neck cancer risk: Pooled analysis in the international head and neck cancer epidemiology consortium. Cancer Epidemiol Biomarkers Prevention 2008;17:1974-81.

33. Ueta I, Saito Y, Teraoka K, Miura T, Jinno K. Determination of volatile organic compounds for a systematic evaluation of third-hand smoking. Anal Sci 2010;26:569-74.

34. Siddiqi K, Shah S, Abbas SM, Vidyasagaran A, Jawad M, Dogar $\mathrm{O}$, et al. Global burden of disease due to smokeless tobacco consumption in adults: Analysis of data from 113 countries. BMC Med 2015;13:194.

35. Awan KH, Patil S. Association of smokeless tobacco with oral cancer Evidence from the South Asian studies: A systematic review. J Coll Physicians Surg Pak 2016;26:775-80.

36. Sinha DN, Abdulkader RS, Gupta PC. Smokeless tobacco-associated cancers: A systematic review and meta-analysis of Indian studies. Int $\mathrm{J}$ Cancer 2016;138:1368-79.

37. Bakdash A. Shammah (Smokeless Tobacco) and Public Health Asian Pac J Cancer Prev 2017;18:1183-90.

38. Khan Z, Suliankatchi RA, Heise TL, Dreger S. Naswar (Smokeless Tobacco) use and the risk of oral cancer in Pakistan: A systematic review with meta-analysis. Nicotine Tob Res 2019;21:32-40.

39. Bhisey RA, Ramchandani AG, D'Souza AV, Borges AM, Notani PN. Long-term carcinogenicity of pan masala in Swiss mice. Int J Cancer 1999;83:679-84.

40. Kumar S. Indian state bans tobacco based chewing products. BMJ 2002;325:184.

41. Idris AM, Ibrahim SO, Vasstrand EN, Johannessen AC, Lillehaug JR, Magnusson B, et al. The Swedish snus and the Sudanese toombak: Are they different? Oral Oncol 1998;34:558-66.

42. Stepanov I, Jensen J, Hatsukami D, Hecht SS. New and traditional smokeless tobacco: Comparison of toxicant and carcinogen levels. Nicotine Tob Res 2008;10:1773-82.

43. Rouatbi S, Mezghenni S, Ayachi M, Benzarti M. Women smoking in the Tunisian center: Socio demographic characteristics and effects on functional respiratory parameters. Tunis Med 2015;93:287-93.

44. Granero R, Sánchez M. Changes in tobacco use and related factors in Junior High School students, Lara State, Venezuela, 2000-2003. Cad Saude Publica 2006;22:1893-9. 
45. Renner CC, Patten CA, Enoch C, Petraitis J, Offord KP, Angstman S, et al. Focus groups of Y-K Delta Alaska Natives: Attitudes toward tobacco use and tobacco dependence interventions. Preventive Med 2003;38:421-31.

46. Ugen S. Bhutan: The world's most advanced tobacco control nation? Tob Control 2003;12:431-3.

47. Goldstein BY, Chang SC, Hashibe M, Vecchia CL, Zhang ZF. Alcohol consumption and cancer of the oral cavity and pharynx from 1988 to 2009: An update. Eur J Cancer Prev 2010;19:431-65.

48. World Health Organization. Global Status Report on Alcohol and Health. World Health Organization; 2014. P. 115. Available from: http://www.who.int/substance_abuse/publications/global_ alcohol_report/msb_gsr_2014_1.pdf?ua=1(link is external). [Last accessed 2018 May 08].

49. Sacks JJ, Gonzales KR, Bouchery EE, Tomedi LE, Brewer RD. 2010 national and state costs of excessive alcohol consumption. Am J Prev Med 2015;49:e73-9.

50. Zhang Y, Wang R, Miao L, Zhu L, Jiang H, Yuan H. Different levels in alcohol and tobacco consumption in head and neck cancer patients from 1957 to 2013. Wei Q-Y, ed. PLoS One 2015;10:e0124045.

51. Dasanayake AP, Silverman AJ, Warnakulasuriya S. Maté drinking and oral and oro-pharyngeal cancer: A systematic review and meta-analysis. Oral Oncol 2010;46:82-6.

52. Stefani ED, Moore M, Aune D, Deneo-Pellegrini H, Ronco AL, Boffetta $\mathrm{P}$, et al. Maté consumption and risk of cancer: A multi-site case-control study in Uruguay. Asian Pac J Cancer Prev 2011;12:1089-93.

53. Loria D, Barrios E, Zanetti R. Cancer and yerba mate consumption: A review of possible associations. Rev Panam Salud Publica 2009;25:530-9.

54. Sherman MP, Aeberhard EE, Wong VZ, Simmons MS, Roth MD, Tashkin DP. Effects of smoking marijuana, tobacco or cocaine alone or in combination on DNA damage in human alveolar macrophages. Life Sci 1995;56:2201-7.

55. de Carvalho MF, Dourado MR, Fernandes IB, Araújo CT, Mesquita AT, Ramos-Jorge ML. Head and neck cancer among marijuana users: A meta-analysis of matched case-control studies. Arch Oral Biol 2015;60:1750-5.

56. Lu CT, Yen YY, Ho CS, Ko YC, Tsai CC, Hsieh CC, et al. A case-control study of oral cancer in Changhua County, Taiwan. J Oral Pathol Med 1996;25:245-8.

57. IARC. Monographs on the Evaluation of Carcinogenic Risks to
Humans. Vol. 85. Betel-quid and Areca-nut Chewing and Some Areca-nut Related Nitrosamines, Lyon: IARC; 2004a.

58. Balaram P, Sridhar H, Rajkumar T, Vaccarella S, Herrero R, Nandakumar A, et al. Oral cancer in Southern India: The influence of smoking, drinking, paan-chewing and oral hygiene. Int J Cancer 2002;98:440-5.

59. Furniss CS, McClean MD, Smith JF, Bryan J, Applebaum KM, Nelson HH, et al. Human papillomavirus 6 seropositivity is associated with risk of head and neck squamous cell carcinoma, independent of tobacco and alcohol use. Ann Oncol 2009;20:534-41.

60. Kuo RC, Lin CY, Kuo MY. Prognostic role of c-Jun activation in patients with areca quid chewing-related oral squamous cell carcinomas in Taiwan. J Formos Med Assoc 2006;105:229-34.

61. Chaturvedi AK. Epidemiology and clinical aspects of HPV in head and neck cancers. Head Neck Pathol 2012;6 Suppl 1:S16-24.

62. Murthy V, Calcuttawala A, Chadha K, d'Cruz A, Krishnamurthy A, Mallick I, et al. Human papillomavirus in head and neck cancer in India: Current status and consensus recommendations. South Asian J Cancer 2017;6:93-8.

63. Chancellor JA, Ioannides SJ, Elwood JM. Oral and oropharyngeal cancer and the role of sexual behaviour: A systematic review. Community Dent Oral Epidemiol 2017;45:20-34.

64. Wenger LD, Malone RE, George A, Bero LA. Cigar magazines: Using tobacco to sell a lifestyle. Tob Control 2001;10:279-84.

65. Bedi R. Betel-quid and tobacco chewing among the United Kingdom's Bangladeshi community. $\mathrm{Br}$ J Cancer Suppl 1996;29:S73-7.

66. Al-Maweri SA, Tarakji B, Alsalhani AB, Al-Shamiri HM, Alaizari NA, Altamimi MA, et al. Oral cancer awareness of the general public in Saudi Arabia. Asian Pac J Cancer Prev 2015; 16:3377-81.

67. Soneji S, Sargent J, Tanski S. Multiple tobacco product use among US adolescents and young adults. Tob Control 2016;25:174-80.

68. Jovanovic A, Schulten EA, Kostense PJ, Snow GB, van der Waal I. Tobacco and alcohol related to the anatomical site of oral squamous cell carcinoma. J Oral Pathol Med 1993;22:459-62.

69. Lad N, Patil D, Pilankar A, Kadam R. Advocacy with police department for effective implementation of tobacco control polices. Tobacco Induced Dis 2018;16:63. 